\title{
Editorial
}

\section{ADBHUT MATRUTVA}

\section{Incredible Motherhood}

Motherhood is a unique experience which is incomparable to anything in this world. Our mothers are the creators of this world and are precious, so are our babies and both deserve the best of care and compassion so that this journey to motherhood be not only an experience in itself but should be carried out in such a way that the journey is enjoyable and future generations are healthy.

We have learned from the history that children conceived and born during famines, especially in the famous Dutch Hunger Winter, had many health issues in later life. Many studies were done on this population and it was observed that depending on the time of

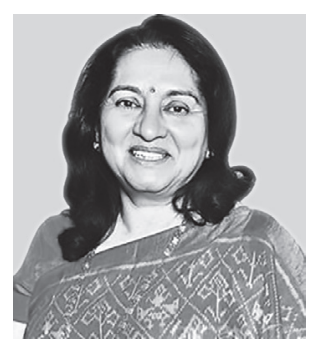
exposure, people suffered from infertility and those in first trimester had obesity and heart disease, and in second trimester, they experienced airway disease and diabetes and in third trimester, they had insulin resistance and diabetes. In another study from a small village in Gambia showed that children born in the wet hungry season were ten times more likely to die prematurely than those born during the dry harvest season. They also had different levels of activity of a gene particulary regulating immune system. The study also showed that these babies had different weight and head circumference depending on the methylation patterns according to the seasons in which they were born.

In Indian history, the Sanskrit word Garbh means foetus in the womb and Sanskar means educating the mind. So, Garbh Sanskar essentially means educating the mind of the foetus. It is traditionally believed that a child's mental and behavioral development starts as soon as he/she is conceived. His/her personality begins to take shape in the womb, and this can be influenced by the mother's state of mind during pregnancy. This knowledge can be traced back to ancient scriptures and is included in the Ayurvedas been followed from time immemorial and a lot of traditional practices are now coming out with concrete scientific evidences, which the world is now researching on today. It is an emerging belief that the origin of many adult diseases lies in utero and curbing the insults to the pregnant mother nutritionally, emotionally, and bodily can have deep impact on the health, neurocognitive, and many noncommunicable diseases (NCDs) developing in later life.

Time has now come, where we as healthcare providers should not only be looking at provision, but quality and respectful, evidence-based healthcare should also be emphasized. With NCDs leading cause of death and our region contributing majorly for the number of diabetics in the world, with maximum numbers of preterm babies being born in our region and obesity on the rise, definitely there are many things which we are not doing right.

As healthcare providers, our major aim in the past few decades has been to provide care and concentrate on institutional deliveries, but with $82 \%$ institutional deliveries, our maternal and neonatal mortality rates have not come down as they were expected and our infant mortality rates have also not done any better, and deaths due to NCDs are rising exponentially. When we think of theories of fetal origin of adult diseases and Garbh Sanskar and along with all the initiatives from preconception counselling, with directed good antenatal care, from first trimester to postpartum period in a holistic combination, the outcomes will be far reaching on not only the mothers and the children, but also on the whole future generations. This is the concept of ADBHUT MATRUTVA.

Knowing is not enough; we must apply. Willing is not enough; we must do."

Goethe
Dr Jaideep Malhotra MD FICMCH FICOH FRCS FRCOG FMAS FRCPI President FOGSI 2018, India Editor in Chief 